\title{
Precipitable Water Vapor around Orographically Induced Convergence Line
}

\author{
Hiroaki Kawase ${ }^{1}$, Yoshitaka Takeuchi ${ }^{2}$, Tomonori Sato ${ }^{3}$, and Fujio Kimura ${ }^{4}$ \\ ${ }^{1}$ Graduate School of Life and Environmental Sciences, University of Tsukuba, Tsukuba, Japan \\ ${ }^{2}$ NTT DATA Corporation, Tokyo, Japan \\ ${ }^{3}$ Japan Science and Technology Agency, Kawaguchi, Japan \\ ${ }^{4}$ Frontier Research Center for Global Change, Yokohama, Japan
}

\begin{abstract}
During the winter monsoon, a convergence line called the Boso Front often appears in the area between the Kanto Plain and the Izu Islands, Japan. Two typical cases of high-level Precipitable Water Vapor (PWV) are observed along the convergence line in the lee of Chubu Mountains by the aid of latest techniques of Global Positioning System (GPS).

Statistic analysis of GPS derived Precipitable Water Vapor (GPS-PWV) indicates that the prevailing wind direction controls the position of the high-level $\mathrm{PWV}$ in the lee of Chubu Mountains. A numerical model simulates the behavior of water vapor, namely, the temporal variation of simulated PWV and surface wind, which suggest the reasons for the high PWV near the convergence line. The convergence of surface wind gathers moisture, and trapped moisture by reduced wind velocity may also contribute the high-level PWV.
\end{abstract}

\section{Introduction}

The Japan Islands are often covered by a cold northwesterly wind during the winter monsoon. The wind going over the Chubu Mountains produces clear sky and a dry atmosphere on the lee side. The northwesterly wind often separates into two mesoscale wind systems by the mechanical effects of the mountains. One goes around the northeastern side of the Chubu Mountains, and the other goes around the southwestern side of them. These two wind systems converge over the Pacific Ocean or the Kanto Plain which is located in the lee of the Chubu Mountains. The convergence lines appearing over the Kanto Plain were investigated in previous studies (Kawamura 1966; Nishina 1984). Kawamura (1966) investigated in situ observation wind data and reported that the convergence line called the "Boso Front" appears over the Kanto Plain. The Boso Front may contribute to cloud formation and even rainfall and snow. Since his analysis was limited in surface wind data observed once a day, temporal variation of the convergence line has not been understood well.

Kawase et al. (2005) investigated many thick cloud streets along convergence lines in the lee of the Japan Arcs using a numerical model and satellite images. They indicated that most of the convergence lines appear as a result of both the mechanical effects of the topography and thermal effects between land and sea of the Japan Arcs. The mechanical effects of the mountains will be predominant in case of the convergence line appearing in the lee of the Chubu Mountains, which have a larger horizontal scale than convergence lines formed by thermal effects mentioned above.

Corresponding author: Hiroaki Kawase, University of Tsukuba, 1-1-1 Tennoudai, Tsukuba 305-8572, Japan. E-mail: s0335356@ ipe.tsukuba.ac.jp. (C2006, the Meteorological Society of Japan.
The structures of the wind, cloud, and temperature near the convergence line were reported in previous studies. However, the distribution of water vapor, which is a key factor for cloud and precipitation, has not been investigated. The purpose of this study is to reveal the water vapor behavior when an orographycally induced convergence line is formed, by using GPS-PWV and high resolved numerical simulations.

In recent years, techniques for estimating Precipitable Water Vapor using the Global Positioning System (GPS-PWV) have been developed (e.g., Bevis et al. 1992). The GPS-PWV data are quite useful to study precipitation systems, since the observation frequency is much higher than that with air soundings by a radiosonde. Niimura et al. (2000) clarified the statistical relationship between PWV and precipitation in the Kanto region using three-hourly time averaged GPS-PWV data. Using GPS-PWV and numerical experiments, Okamura and Kimura (2003) investigated the mesoscale disturbance that is sometimes generated after a cold front passes in the Kanto Plain. They indicated that the orographic modulation of the prevailing wind by the Chubu mountains is very important for the distribution of PWV and abrupt development of the mesoscale disturbances over the Kanto Plain.

\section{Distribution of observed GPS-PWV}

Three-hourly GPS zenith delay data are provided by the Geographical Survey Institute (GSI) in Japan. The GSI has established over 1000 GPS observation sites. The mean horizontal interval between stations is about $20 \mathrm{~km}$. The GPS zenith delay was converted into PWV using nearest in situ meteorological data obtained by

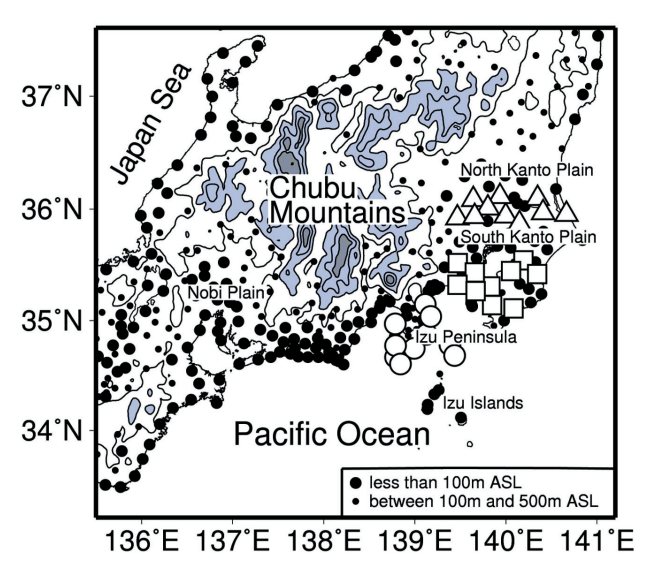

Fig. 1. Positions of GPS stations and a topography in the central Japan Mainland. Contour interval is $500 \mathrm{~m}$. Large open circles, triangles, and squares are located less than $100 \mathrm{~m}$ ASL and are used for the statistical analysis in Section 4. 


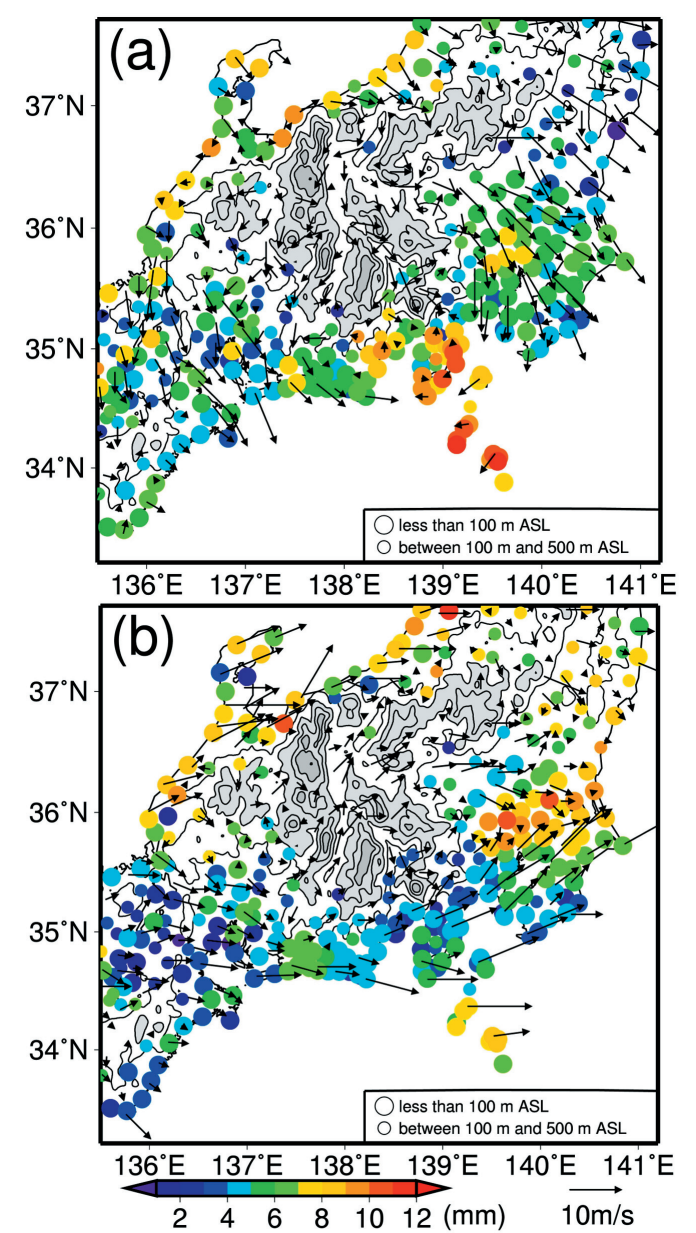

Fig. 2. Distribution of the three-hourly mean GPS-PWV and surface wind. (a) from 12 JST to 15 JST on Dec. 3 1999. (b) from 15 JST to 18 JST on Dec. 10 1997. Contour interval is $500 \mathrm{~m}$.

the Japan Meteorological Agency. The accuracy of GPS$\mathrm{PWV}$ is sufficient for this analysis even in winter (Supplement 1).

Since PWV, vertical integration of water vapor, is strongly dependent on the altitude, it is difficult to compare PWV among stations at different altitudes. The horizontal distribution of PWV can be estimated only by GPS stations located in a small altitude difference. Figure 1 shows the topography and the positions of GPS stations in the central Japan Mainland. The altitudes of some peaks in the Chubu Mountains are more than 3000 m. Large filled circles indicate the GPS stations located at less than $100 \mathrm{~m}$ above sea level (ASL), while small filled circles indicate the stations at between $100 \mathrm{~m}$ and $500 \mathrm{~m}$ ASL. Large open circles, triangles, and squares also locate less than $100 \mathrm{~m} \mathrm{ASL}$ and are used for the statistical analysis in Section 4.

The convergence line is often observed over the Kanto Plain or the Izu Peninsula during the winter monsoon. Two typical cases are selected. The first case was observed on Dec. 31999 when a northwesterly wind prevailed on the surface, and the second case was observed on Dec. 101997 when a westerly wind prevailed.

During the first case, a cyclone is located southwest of Sakhalin with a cold front, which is extending southeastward over the Pacific Ocean, while an anticyclone is located over northeastern China. This is a typical pattern of surface pressure during the winter monsoon.
The pressure system indicates a strong eastward pressure gradient over the central Japan Mainland (figure not shown).

Figure $2 \mathrm{a}$ shows three-hourly averaged GPS-PWV and surface wind during 12 JST (JST $=$ UTC +9 hours) to 15 JST on Dec. 3 1999. The colors of the circles show the amount of GPS-PWV, and the vectors show the surface wind speed and direction observed by the Automated Meteorological Data Acquisition System (AMeDAS). GPS-PWV plotted by small circles, which are located at the altitude between $100 \mathrm{~m}$ and $500 \mathrm{~m}$ ASL, tend to be lower than other stations in their neighbor, which are shown by large circles, because of the altitude effect. A northwesterly wind prevails in the central Japan Mainland. The wind direction tends to be northerly in the southeastern part of the Kanto Plain, while it further veers northeasterly over the Izu Islands. On the other hand, the Nobi Plain is covered by a northwesterly wind. These two wind systems, passing through the Kanto Plain and through the Nobi Plain, seem to converge at west of the Izu islands.

High GPS-PWV of about $8 \mathrm{~mm}$ is observed along the Japan Sea coast, while it is only about $5 \mathrm{~mm}$ along the coast of the Pacific Ocean as well as in the Kanto Plain and the Nobi Plain. The GPS-PWV is exceptionally high, nearly $12 \mathrm{~mm}$, in the Izu Peninsula and the Izu Islands. The altitude effect on PWV does not seem to mislead the distribution of high-level GPS-PWV around the Izu Peninsula.

In the second case, the distribution of the surface pressure is similar to that of the first case, but the pressure gradient is northeastward over the central Japan Mainland (figure not shown). Figure 2b shows three-hourly averaged GPS-PWV and surface wind from 15 JST to 18 JST on Dec. 10 1999. A strong westerly wind nearly covers the central Japan Mainland. The North Kanto Plain is covered by a northwesterly wind, while the South Kanto Plain and the Izu Peninsula are covered by a southwesterly wind. These two wind systems converge over the center of the Kanto Plain.

Along the Japan Sea coast, a high GPS-PWV similar to that shown in Fig. $2 \mathrm{a}$ is observed. The GPS-PWV is quite low at the Pacific coast except for the center of the Kanto Plain. The GPS-PWV is exceptionally high, about $10 \mathrm{~mm}$, in the center of the Kanto Plain, whereas very low GPS-PWV was observed in the first case (Fig. 2a). The level of GPS-PWV is quite low, about $5 \mathrm{~mm}$ in the Izu Peninsula, and slightly higher, about $7 \mathrm{~mm}$ in the Izu Islands where high GPS-PWV was observed in the first case (Fig. 2a).

\section{Numerical simulations}

The behavior of water vapor in these cases is simulated by a non-hydrostatic numerical model, TERCRAMS. The TERC-RAMS is a modified version of the Regional Atmospheric Modeling System (RAMS) (see Supplement 2) presented by Yoshikane et al. (2001), Sato and Kimura (2005). The original RAMS was developed at Colorado State University (Pielke et al. 1992).

Two-way nested grid system is adopted. The coarsegrid system, which has a large grid interval of $20 \mathrm{~km}$, covers all of Japan, while a fine-grid system has a small grid interval of $5 \mathrm{~km}$ that is high enough to simulate the barrier effects of the Chubu Mountains. The height of the model atmosphere is $19 \mathrm{~km} \mathrm{ASL}$ and is divided into 30 layers. The initial condition for the coarse-grid system is interpolated from the global reanalysis data provided by the National Center for Environmental Prediction (NCEP)/National Center for Atmospheric Research (NCAR). The initial time is set to be 09 JST 

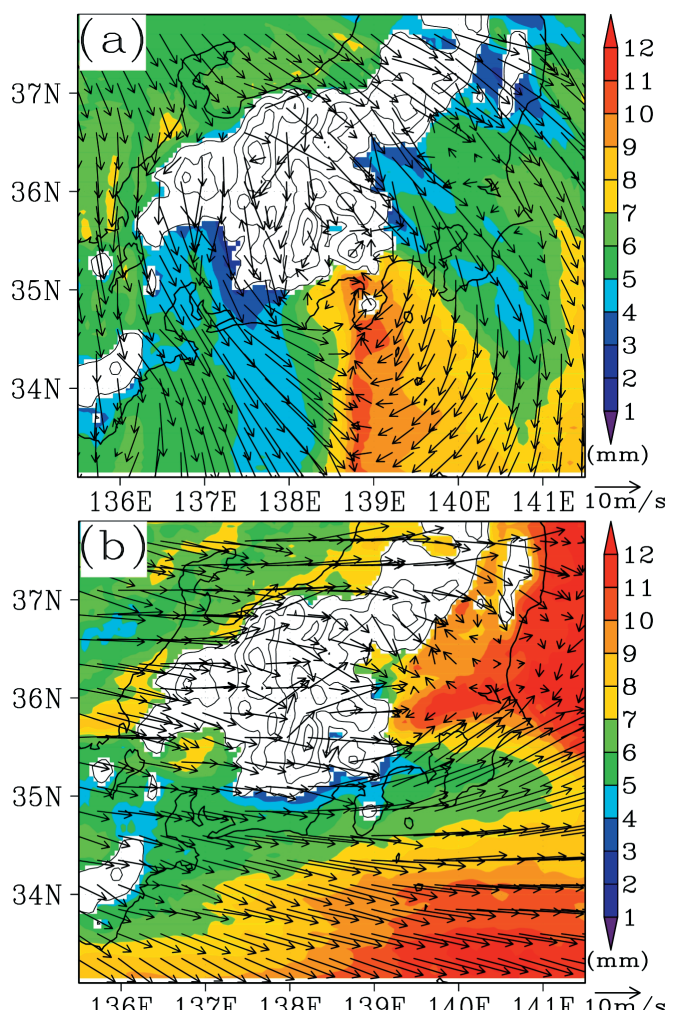

Fig. 3. Distribution of PWV and surface wind simulated by the numerical model. (a) from 12 JST to 15 JST on Dec. 3 1999. (b) from 15 JST to 18 JST on Dec.10 1997.

Dec. 2 1999, for the first case and 09 JST Dec. 9 1997, for the second case. The lateral boundary conditions of the coarse-grid system are time-interpolated from the sixhourly reanalysis data. The sea surface temperature (SST), which is assumed to be constant during the integration period, is specified using the monthly mean SST data (Reynolds and Smith 1994).

Figure 3a shows the PWV (shade) and surface wind speed and direction (arrows) simulated by the numerical model corresponding to Fig. 2a. The PWV is masked in the region where the altitude is higher than $500 \mathrm{~m}$. The model simulates low-PWV regions in the Kanto and Nobi Plains, which extend leeward. Except for the Izu Peninsula, the simulated PWV along the Pacific coast is lower than that along the coast of the Japan Sea. PWV is quite high around the Izu Islands and the Izu Peninsula. The northeasterly wind from the Kanto Plain and the northwesterly wind from the Nobi Plain converge to the west of the Izu Islands, where a high PWV is simulated. These results are consistent with the observation (Fig. 2a).

Figure $3 \mathrm{~b}$ shows the result of numerical simulation for the second case corresponding to Fig. 2b. The distribution of PWV is consistent with the observation, although the PWV is slightly overestimated. High PWV is simulated over the center of the Kanto Plain, while low PWV is simulated over the Nobi Plain and the Izu Peninsula. Mild wind (less than $2 \mathrm{~m} / \mathrm{s}$ ) prevails over the Kanto Plain, where two wind systems converge; namely, one is the southwesterly wind passing through the Nobi Plain and the Izu Peninsula, and the other is the northwesterly wind through the mountain path at the northern boundary of the Kanto Plain. Figure $2 \mathrm{~b}$ shows that observed PWV is high also over the Izu Islands, beside the high PWV over the Kanto Plain mentioned

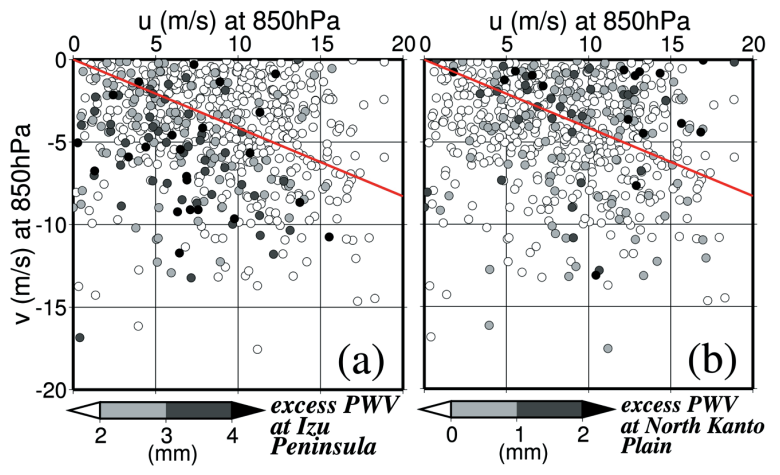

Fig. 4. Scatter diagram of the wind velocity at $850 \mathrm{hPa}$ interpolated from NCEP/NCAR reanalysis data at 09 JST or 21 JST during the winters of 1996 to 2000. The darker shade in the circle indicates that (a) GPS-PWV is higher in the Izu Peninsula than in the other regions (North Kanto and South Kanto Plain) and (b) GPS-PWV is higher in the North Kanto Plain than in the other regions (South Kanto Plain and Izu Peninsula). The red line indicates the direction from WNW to ESE.

above. The simulation indicates that the high-level PWV observed over the Izu Islands (see Fig. 2b) is located neither in the convergence line nor in other disturbances but in a moist air mass originated in the Pacific Ocean.

\section{Discussion}

The analysis of GPS-PWV and the numerical simulations show the increase of PWV near the convergence line in the case studies. The convergence line with highlevel PWV is generated over the Izu Islands and the Izu Peninsula in the first case, when the northwesterly wind prevails over the central Japan Mainland. On the other hand, when the westerly wind prevails, as in the second case, high-level PWV is generated over the Kanto Plain.

The position of the convergence line in the lee of the Chubu Mountains should depend on the synoptic wind speed and direction (Kawamura 1966; Nishina 1984). Figure 4 is a scatter diagram of the wind velocity at 850 $\mathrm{hPa}$ observed at 09 JST or 21 JST from November through March from 1996 to 2000. The horizontal and vertical axes mean the zonal component and meridional component of the mean wind, respectively, over the central Japan Mainland $(35 \mathrm{~N}-37.5 \mathrm{~N}, 137.5 \mathrm{E}-140 \mathrm{E})$ obtained by NCEP/NCAR reanalysis data.

The shading in Fig. $4 \mathrm{a}$ indicates the difference in the area-mean GPS-PWV between the Izu Peninsula and the two other regions. The area-mean GPS-PWV is estimated as an average of ten stations over three different regions as shown in Fig. 1, namely, the Izu Peninsula (open circle), South Kanto Plain (open square), and North Kanto Plain (open triangle). Each region includes many GPS stations which are located below $100 \mathrm{~m}$ ASL, and ten stations are selected. The mean GPS-PWV at 09 and $21 \mathrm{JST}$ is interpolated from three-hourly averaged data.

The darker shading in Fig. 4a indicates that GPSPWV is higher in the Izu Peninsula than it is in the other regions. Most of the dark-shaded circles are plotted below the red line, indicating the direction from WNW to ESE; namely, the PWV is enhanced over the Izu Peninsula when the direction of the prevailing wind is between $\mathrm{N}$ and WNW.

The Izu Peninsula is located in the lee of the Chubu Mountains when a wind direction is between N and NW. The first case study in Section 2 indicates GPS-PWV is 
high in the Izu Peninsula where the convergence line is located. The high GPS-PWV in Fig. 4a should be associated with the convergence line that forms in the lee of the Chubu Mountains.

Figure $4 \mathrm{~b}$ is the same as Fig. 4a except for the excess of GPS-PWV in the North Kanto Plain in comparison with the average of two other regions. The range of the shading is $2 \mathrm{~mm}$ (light) to $4 \mathrm{~mm}$ (dark) in Fig. $4 \mathrm{~b}$ and 0 $\mathrm{mm}$ to $2 \mathrm{~mm}$ in Fig. 4a. The dark-shaded circles are plotted above the red line; namely, the PWV is enhanced over the North Kanto Plain when the direction of the prevailing wind is between WNW and W. Similar to the Izu Peninsula in the first case, the North Kanto Plain is located in the lee of the Chubu Mountains when the wind direction is between WNW and W. The high GPSPWV in Fig. 4b should also be associated with the convergence line.

The case studies clarified that the PWV is enhanced by the convergence line in the lee of the Chubu Mountains. The statistical analysis shows that the prevailing wind direction controls the position of the high PWV. The PWV is enhanced over the Izu Peninsula when the prevailing wind is northwesterly but over the North Kanto Plain when the prevailing wind is westerly. These facts are consistent with those of previous studies, which suggest that the convergence line appears quite frequently in the lee of the Chubu Mountains. The PWV becomes locally high along the convergence line.

The numerical simulation of the first case describes the formation process of the high-level PWV near the convergence line as follows. The central Japan Mainland was covered by moist air before a passage of the cold front. After the cold front passed Japan, the humidity dropped in most of the Japan Mainland. But the PWV in the lee of the Chubu Mountains still kept higher level than that in the surrounding area (Supplement 3).

The surface wind is weak and converges over the high-PWV area. The convergence of surface wind should contribute to the formation of high-level PWV in the lee of the Chubu Mountains because of the increase of PWV after 06 JST on Dec 3 as shown in Supplement 3 . Low wind speed in the convergence area implies that the trapped moisture may also contribute to the formation of high-level PWV.

Using a numerical simulation, Kang and Kimura (1997) investigated a cloud street which generates in the convergence line in the lee of isolated mountains. They stated that the cloud street consists of two convective rolls, an inner roll and an outer roll. The outer roll, which has a large horizontal scale but a weak circulation, gathers a large amount of moisture in the lower marine boundary layer. It is speculated that wind systems in both side of the convergence line shown in Fig. $3 \mathrm{a}$ are part of the outer roll stated in Kang and Kimura (1997) and keep the high-PWV along the convergence line.

\section{Conclusion}

During the winter monsoon, a convergence line often appears in the lee of the Chubu Mountains. The analysis of GPS-PWV shows that high-level PWV is observed near the convergence line in the two typical cases. The statistical analysis indicates that the synoptic wind direction controls the position of high-level PWV. Highlevel PWV is generated over the Izu Islands and the Izu Peninsula when a northwesterly wind prevails in the central Japan Mainland. On the other hand, high-level PWV is generated over the Kanto Plain when a westerly wind prevails. These facts mean that PWV becomes locally high along the convergence line. The numerical model simulates the temporal variations of PWV and surface wind, which suggest the convergence of surface wind should contribute to high-level PWV and trapped moisture by reduced wind velocity may also contribute the high-level PWV in the lee of the Chubu Mountains. The horizontal distribution of GPS-PWV contributes to an understanding of the structure of the convergence line in the lee of mountains.

\section{Comments and Supplements}

1. The accuracy of GPS-PWV in winter season (from November through March) from 1996 to 2000.

2. Specification of TERC-RAMS.

3. Temporal variation of PWV and surface wind calculated by TERC-RAMS in the first case at horizontal line (from $137 \mathrm{E}, 33.5 \mathrm{~N}$ to $141 \mathrm{E}, 35 \mathrm{~N}$ ) from 21 JST on Dec. 2 to 15 JST on Dec. 3.

\section{Acknowledgments}

We thank Drs. Y. Hayashi, H. L. Tanaka, K. Ueno, H. Ueda, and other members of meteorology and climatology group in the University of Tsukuba for their helpful suggestions.

\section{References}

Bevis, M., S. Businger, T. A. Herring, C. Rocken, R. A. Anthes, and R. H. Ware, 1992: GPS Meteorology: Remote sensing of atmospheric water vapor using the Global Position System. J. Geophys. Res., 97, 15787-15801.

Kang, S.-D., and F. Kimura, 1997: A numerical study on the mechanism of cloud-street formation in the lee of an isolated mountain near a coast, J. Meteor. Soc. Japan, 75, 955-968.

Kawamura, T., 1966: Surface wind systems over central Japan in the winter season.-with special reference to winter monsoons-. Geographical Review of Japan, 39, 538-554. (in Japanese).

Kawase, H., T. Sato, and F. Kimura, 2005: Numerical experiments on cloud streets in the lee of island arcs during cold-air outbreaks. Geophys. Res. Lett., 32, L14823, doi:10.1029/2005GL023256.

Niimura, N., T. Sasaki, and F. Kimura, 2000: Statistical rela- tion between precipitation and precipitable water vapor obtained from the Global Positioning System (GPS) in Tokyo Metropolitan Area. Tenki, 47, 635-642. (in Japanese).

Nishina, J., 1984: An Orographic effect on the cloud distribution around the central Japan under the winter monsoon situation. Geographical Review of Japan, 57, 329-348. (in Japanese).

Okamura, O., and F. Kimura, 2003: Behavior of GPS-derived precipitable water vapor in the mountain lee after the passage of a cold front. Geophys. Res. Lett., 30, 1746, doi:10.1029/2003GL017572.

Pielke, R. A., W. R. Cotton, R. L. Walko, C. J. Tremback, W. A. Lyons, L. Grasso, M. E. Nicholls, M. D. Moran, D. A. Wesley, T. J. Lee, and J. H. Copeland, 1992: A comprehensive meteological modeling system-RAMS. Meteor. Atmos. Phys., 49, 69-91.

Reynolds, R. W., and T. M. Smith, 1994: Improved global sea surface temperature analyses using optimum Interpolation. J. Climate, 7, 929-948.

Sato, T., and F. Kimura, 2005: Diurnal cycle of convective instability around the central mountains in Japan during the warm season, J. Atmos. Sci., 62, 1626-1636.

Yoshikane, T., F. Kimura, and S. Emori, 2001: Numerical study on the Baiu Front genesis by heating contrast between land and ocean, J. Meteor. Soc. Japan, 79, 671-686.

Manuscript received 25 November 2005, accepted 2 February 2006 SOLA: http://www.jstage.jst.go.jp/browse/sola/ 